\title{
Study on total factor productivity of retail industry in east China
}

\section{-- based on Malmquist index}

\author{
Cheng Qiu, Lingjie Meng* \\ Nanjing University of Science and Technology,School of Economics and Management, China \\ *Corresponding author: Lingjie Meng, Professor, mlj339@aliyun.com
}

\begin{abstract}
Based on the Malmquist index method of data envelopment analysis (DEA), the total factor productivity (TFP) of the retail industry in East China was measured by using the panel data from 2008 to 2015. After that, the TFP was decomposed into technical efficiency change and technological progress. The results showed that the average annual growth rate of TFP in the retail industry is $0.8 \%$ between 2008 and 2015, mainly due to the change of technological progress. At the same time, there are significant differences in the TFP of the six provinces and one city in East China, and the more developed the economy, the higher the growth rate.
\end{abstract}

Key words: retail industry; TFP; technical efficiency change; technological progress; East China

\section{Introduction}

Retail industry is one of the basic industries of people's livelihood. Since the reform and opening up in 1978, the total retail sales of social consumer goods grew by an average of 15.3\%. There were 91258 retail enterprises with more than 6.88 million employees in 2015, and the total retail sales of social consumer goods reached 30093 billion yuan, representing an increase of $10.7 \%$ in nominal terms in 2014. The retail industry has developed rapidly in China. However, another unquestionable fact is that since 2011, China's retail enterprises have been faced with high cost, high competition, low return, and other problems. Especially on the background of the continuous development of e-commerce, inefficient traditional retail model is gradually being broken, the traditional retailers feel the growing pressure.

East China is one of the regions with the highest level of economic development in China, as well as its retail scale. Therefore, the study of East China's retail industry and the total factor productivity is representative. This paper used the Malmquist index method based on data envelopment analysis (DEA) to analyze the total factor productivity of the retail industry. We 
study the evolution law of space-time of the retail industry and the regional differences. With the results, we hope to provide advice and reference in how to improve the efficiency of the retail industry in East China.

While the relative research on retail productivity is relatively scarce compared to other areas, foreign researchers have also developed some retail productivity measurement methods. Charnes et al. (1978) ${ }^{1}$ first introduced DEA as a decision-making unit's assessment tool to measure retail productivity. Donthu \& Yoo $(1998)^{2}$ argued that previous research ignored micro-level research, and it was also necessary to use micro-tools to measure retail productivity. Debabrata et al. (2010) ${ }^{3}$ found that demand-related factors (demand growth, price) and competitive factors (location, advertising, service, quality) were important in estimating productivity when studying retail productivity in New Zealand and Australia. Mitsuru Sunada (2010) ${ }^{4}$ used a discrete selection model based on microdata to study the Japanese retail productivity. Atsuyuki Kato (2012) ${ }^{5}$ of the Asian Development Bank used the Japanese company-level data and the CES production function to analyze the productivity and returns to scale. The direct research on the calculation of retail industry productivity in China is relatively lacking, but there are some researches on the technology progress and performance evaluation of retail industry. Representative studies include: Lei Lei (2013) ${ }^{6}$ studied the total factor productivity of retail listed companies. Su Liu (2013) ${ }^{7}$ studied the macro marketing efficiency of wholesale and retail trade in China. Bo Yang (2012) ${ }^{8}$ studied the operating efficiency of the listed companies in China's retail industry.

\section{Research tools and methods}

\subsection{DEA method}

There are many ways to evaluate efficiency, and DEA is a commonly used nonparametric method. DEA has unique advantages: first, it can evaluate the multi-input and multi-output (or single output) of the decision-making issues, and it's more flexible. Second, before the evaluation of efficiency, it is not necessary to set the specific form and error items distribution of production function, and this avoid the impact of the subjective factors. Third, when dealing with panel data, it constructs a frontier in each period, so it is closer to the actual situation.

\subsection{Malmquist productivity index}

In this paper, the DEA-based Malmquist index method constructed by Fare et al. (1994) ${ }^{9}$ was 
used to measure the productivity of China's retail industry. The basis of the construction of the Malmquist index is the distance function, and it is the inverse of Farrell's technical efficiency:

$$
D_{i}^{t}\left(x_{t}, y_{t}\right)=1 / F_{i}^{t}\left(y_{t}, x_{t} \mid C, S\right)
$$

The bigger the $D_{i}^{t}\left(x_{t}, y_{t}\right)$ is, the more efficient the production, and the higher the level of technical efficiency.

$\mathrm{T}$ period to $\mathrm{t}+1$ period, using the t-period technology as a reference, based on the output angle of the Malmquist index is defined as:

$$
M_{i}^{t}\left(x_{t}, y_{t}, x_{t+1}, y_{t+1}\right)=\frac{D_{i}^{t}\left(x_{t+1}, y_{t+1}\right)}{D_{i}^{t}\left(x_{t}, y_{t}\right)}
$$

And $t$ period to $t+1$ period, using the $t+1$ period technology as a reference, based on the output angle of the Malmquist index is defined as:

$$
M_{i}^{t+1}\left(x_{t}, y_{t}, x_{t+1}, y_{t+1}\right)=\frac{D_{i}^{t+1}\left(x_{t+1}, y_{t+1}\right)}{D_{i}^{t+1}\left(x_{t}, y_{t}\right)}
$$

Caves, Christensen and Diewert $(1982)^{10}$ measured Malmquist Index of the total factor productivity growth (TFPG) from the $t$ period to the $t+1$ by using the geometric mean of the Eq. (2) and Eq. (3) with reference to the Fisher ideal index constructor:

$$
M_{i, t+1}\left(x_{t}, y_{t}, x_{t+1}, y_{t+1}\right)=\left[\frac{D_{i}^{t}\left(x_{t+1}, y_{t+1}\right)}{D_{i}^{t}\left(x_{t}, y_{t}\right)} \times \frac{D_{i}^{t+1}\left(x_{t+1}, y_{t+1}\right)}{D_{i}^{t+1}\left(x_{t}, y_{t}\right)}\right]^{1 / 2}
$$

It represents the productive forces of production point $\left(x_{t}, y_{t}\right)$ compared to $\left(x_{t+1}, y_{t+1}\right)$. Eq. (4) can be divided into two parts:

$$
M_{i, t+1}\left(x_{t}, y_{t}, x_{t+1}, y_{t+1}\right)=\frac{D_{i}^{t+1}\left(x_{t+1}, y_{t+1}\right)}{D_{i}^{t}\left(x_{t}, y_{t}\right)} \times\left[\frac{D_{i}^{t}\left(x_{t+1}, y_{t+1}\right)}{D_{i}^{t+1}\left(x_{t+1}, y_{t+1}\right)} \times \frac{D_{i}^{t}\left(x_{t}, y_{t}\right)}{D_{i}^{t+1}\left(x_{t}, y_{t}\right)}\right]^{1 / 2}
$$

That is:

$$
M_{i, t+1}\left(x_{t}, y_{t}, x_{t+1}, y_{t+1}\right)=T E C_{i}^{t+1} \times T P_{i}^{t+1}
$$

The $M$ value greater than 1 represents a positive TFP growth from period $t$ to $t+1$. The Malmquist index is divided into technical efficiency change (TEC) and technological change (TC). TEC $>1$ represents the production of decision-making units closer to the production frontier, and the TEC has increased. TC is the technical progress index, which measures the 
movement of the technical boundaries from period t to $t+1$. TC $>1$ represents technological progress, the other is technological downturn.

Technical efficiency (TEC) was divided as a product of pure technical efficiency index (PEC) and scale efficiency index (SEC) by Fare under the circumstances of constant returns to scale (CRS).

$$
\operatorname{TEC}_{i}^{t+1}=\frac{D_{i}^{t+1}\left(x_{t+1}, y_{t+1} \mid C\right)}{D_{i}^{t}\left(x_{t}, y_{t} \mid C\right)}=\frac{S E_{i}^{t+1}\left(x_{t+1}, y_{t+1}\right)}{S E_{i}^{t}\left(x_{t}, y_{t}\right)} \times \frac{D_{i}^{t+1}\left(x_{t+1}, y_{t+1} \mid V\right)}{D_{i}^{t}\left(x_{t}, y_{t} \mid V\right)}
$$

In Eq. (7), the first part of the right end is the change of scale efficiency, and the second is the change of pure technical efficiency:

$$
T E C=S E C \times P E C
$$

Comparing with this model in the manufacturing sector, it is actually more suitable for the calculation of TFP in the service sector. First, the Malmquist productivity index does not require assumptions about the production function, which helps to improve the accuracy of its estimation. Second, there is no need for information on the price of inputs and outputs in the calculation of TFP.

\section{Empirical analysis}

\subsection{Data collection and indicator selection}

The empirical study of this paper takes the six provinces and one city in east China (Shanghai, Jiangsu, Zhejiang, Anhui, Fujian, Jiangxi and Shandong) as the initial samples, and the relevant indicators are selected through the data published by the National Bureau of Statistics. The indicators which estimated the TFP in East China are mainly output indicators and input indicators. Three indicators of input and two indicators of output were selected from the many indicators. They are shown in Table 1.

From the input indicators, the total assets can reflect the retail industry's capital investment, the number of practitioners can reflect the size of the industry, the main business costs reflect the cost of the industry. From the output indicators, the total operating income reflects the retail business of various business activities, and the main business profits directly reflects the industry's retail efficiency, resource utilization level.

After analysis of the initial data, we found that the scale of retail industry in East China is expanding year by year. However, the expansion rate is gradually reduced, and the number of employees in 2015 had negative growth, which may be the result of deepening the application of information technology. 
Table 1 - Input - output indicator

\begin{tabular}{|l|c|c|}
\hline Types & Indicators & Unit \\
\hline \multirow{3}{*}{ Input } & Total assets & Hundred million Yuan \\
\cline { 2 - 3 } & Number of employees & Person \\
\cline { 2 - 3 } & Main business cost & Hundred million Yuan \\
\hline \multirow{3}{*}{ Output } & Total operating income & Hundred million Yuan \\
\cline { 2 - 3 } & Main business profits & Hundred million Yuan \\
\hline
\end{tabular}

\subsection{Results and discussion}

\subsubsection{Time Series Analysis of TPF in Retail Industry in East China}

Based on the Malmquist productivity index theory, we measured the retail productivity index and its decomposition index in East China in 2008-2015. The results are shown in Table 2.

In the Table 2, we can see that the dynamic change of TFP in retail trade in East China is 1.008 between 2008 and 2015, which means that the TFP of retail in East China was improved 0.8\% compared with that in 2007. Xingkai Liu and Cheng Zhang (2009) ${ }^{11}$ research results show that since the reform and opening up, service industry TFP average growth rate is 2. 5\%, which means the TFP of the retail industry is lower than the entire service sector. In addition, in recent years except to 2008-2009,TFP in the retail sector in East China continued to grow. However, the total factor productivity level in the retail industry showed a weak upward trend.

From the results of the index decomposition, the impact of East China's retail TFP growth is the main factor in progress. Expect to 2008-2009 and 2011-2012, the pace of retail technological progress is more than $0.8 \%$. As a result, the average growth rate of technological progress during this period was $0.9 \%$, while the technical efficiency of the same period was almost unchanged, and the technical efficiency and scale efficiency showed a downward trend.

Table 2 shows that the scale efficiency of the retail industry in East China is not much change, the annual rate of change is very small, while pure technical efficiency changes are not changed. The weak changes in scale efficiency and purely technical efficiency in the majority of years have determined the stability of the retail industry in East China, and resulting in a 
lack of contribution to the growth of TFP in the retail sector.

Based on the above analysis, we can see that the main source of TFP growth in retail trade in East China is technological progress. The effect of technical efficiency and scale efficiency is not great. The specific trends are shown in Figure 1. In the long run, technological progress is the main source of all factor productivity changes, so the retail enterprises in East China are supposed to use foreign retail enterprises demonstration effect and technology spillover effect to improve the level of technological progress of retail enterprises. But at the same time, the scale of efficiency changes are not obvious, the results of the revelation is that the companies needs in-depth reorganization of assets to achieve resource sharing and scale expansion.

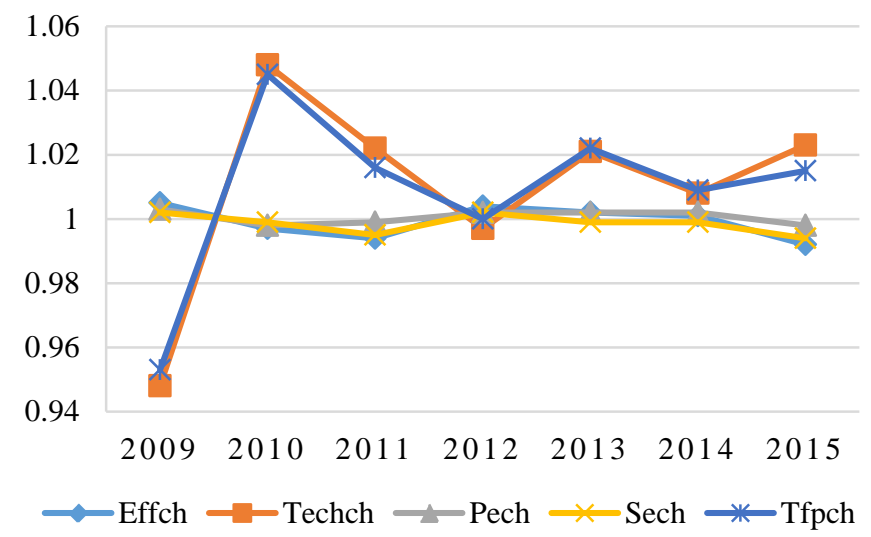

Fig. 1 - Productivity index decomposition and changing trend

\subsubsection{Regional comparison of TFP in retail industry in east China}

For a more comprehensive understanding of the TFP in the retail industry, we use the panel data of the seven provinces and cities in East China during the sample period, and analyze the index change. The results are shown in Table 3.

Table 3 - Regional differences and decomposition of TFP in East China

\begin{tabular}{|l|c|c|c|c|c|}
\hline Province (City) & Effch & Techch & Pech & Sech & Tfpch \\
\hline Shanghai & 1.000 & 1.049 & 1.000 & 1.000 & 1.049 \\
\hline Jiangsu & 1.004 & 1.007 & 1.000 & 1.004 & 1.011 \\
\hline Zhejiang & 0.999 & 1.034 & 1.000 & 0.999 & 1.032 \\
\hline Anhui & 1.000 & 0.996 & 1.003 & 0.997 & 0.996 \\
\hline Fujian & 1.002 & 1.002 & 1.000 & 1.002 & 1.005 \\
\hline Jiangxi & 0.989 & 0.978 & 1.000 & 0.989 & 0.967 \\
\hline Shandong & 1.000 & 0.999 & 1.000 & 1.000 & 0.999 \\
\hline Mean & 0.999 & 1.009 & 1.001 & 0.999 & 1.008 \\
\hline
\end{tabular}


From the results shown in Table 3, the entire TFP in East China increased by $0.8 \%$. Four provinces' TFP have different degrees of growth. During the study period, the highest growth rate of TFP in Shanghai was 4.93\%, followed by Zhejiang Province, reaching 3.2\%. Jiangsu and Shandong grew slowly. While TFP in Jiangxi, Shandong and Anhui declined, showing that the gaps in different province are huge.In terms of several TFP-growing provinces, their total factor productivity growth is mainly due to technological progress. Shanghai's technical efficiency, pure technical efficiency and scale efficiency have not changed, its TFP growth depends entirely on technological progress.

In general, the high growth rate of TFP in Shanghai, Zhejiang, and Jiangsu are the more developed regions in East China and the whole country. These provinces and cities have higher levels of economic development and strong spending power. It can be seen that retail enterprises development and efficiency are inseparable from the local economy. At the same time, by analyzing the growth of TFP in different provinces, the same conclusion can be drawn that the growth of total factor productivity in East China mainly depends on technological progress.

\section{Conclusions}

On the whole, between 2008 and 2015, the average annual growth rate of total factor productivity in East China is $0.8 \%$, mainly due to the improvement of technological progress rather than technical efficiency. Technological progress increased by $0.9 \%$, which indicating the importance of technological progress in East China. From the provincial level, the gap of retail industry TFP growth in the seven provinces and cities is significant. It can be seen that TFP growth is rapid in areas with high per capita consumption. By contrast, in economically underdeveloped areas, TFP growth is slower or even declining. This shows that the development of the retail industry also needs economic development as a support.

There are several ways to improve the total factor productivity of the retail industry in East China. Provinces and cities are supposed to ensure economic growth, and increase per capita disposable income, which will inevitably lead to the development of the retail industry. For specific retail enterprises, they should continue to increase the investment in high-tech input in the enterprise to achieve a higher degree of information technology, which can maintain the continuous growth of technological progress. In addition, companies can conduct in-depth reorganization of assets and merge small enterprises to achieve resource sharing and scale expansion, and this can achieve the goal of enhancing the efficiency of scale. 


\section{References}

1. A.Charnes, W.W.Cooper, E. Rhodes, Measuring the Efficiency of Decision Making Units, J. European Journal of Operational Research 2 (1978) 429-444.

2. N. Donthu, B. Yoo, Retail Productivity Assessment Using Data Envelopment Analysis, J. Journal of Retailing 1 (1998) 89-105.

3. D.Talukdar, D. K. Gauri and D. Grewal, An Empirical Analysis of the Extreme Cherry Picking Behavior of Consumers in the Frequently Purchased Goods Market, J. Journal of Retailing 4 (2010) 336-54.

4. M. Sunada, Measuring the Cost of Living Index, Output Growth, and Productivity Growth in the Retail Industry: an Application to Japan, J. Review of Income and Wealth 4 (2010) 667-692.

5. A. Kato, Productivity, Returns to Scale and Product Differentiation in the Retail Trade Industry: an Empirical Analysis Using Japanese Firm-Level Data, J. J Prod Anal. 38 (2012) 345-353.

6. L. Lei, An Empirical Study on the Growth of Total Factor Productivity of Retail Listed Companies - Based on the Analysis of Malmquist Index, J. Journal of Beijing Technology and Business University(Social Sciences) 6 (2013) 20-26.

7. S. Liu, T. Wan, J. Xie, Y. Mao, Analysis on Macro - marketing Efficiency Factor of China 's Wholesale and Retail Industry, J. Statistics \& Decision 5 (2013) 61-64.

8. B. Yang, Evaluation and Analysis on the Operating Efficiency of China 's Retail Listed Companies, J. Journal of Shanxi University of Finance and Economics 1 (2012) 52-61.

9. R.Färe, S.Grosskopf, M.Norris, Productivity Growth, Technical Progress, and Efficiency Change in Industrialized Countries: Reply, J. American Economic Review 5 (1994) 1040-1044.

10. D. W.Caves, L. R.Christensen, W. E.Diewert, The Economic Theory of Index Numbers and the Measurement of Input, Output, and Productivity, J. Econometrica. 6 (1982) 1393-1414.

11. X. Liu, C. Zhang, Analysis of Total Factor Productivity Growth and Its Convergence in China 's Service Industry, J. The Journal of Quantitative \& Technical Economics 3 (2010) 55-67. 